\title{
Libros Blancos de Defensa en Sudamérica: ¿Política exterior o política doméstica?
}

\section{Defense White Papers in South America: Foreign policy or domestic politics?}

Rev. Bras. Est. Def. v. 4, nº 2, jul./dez. 2017, p. 17-48

DOI: $10.26792 /$ RBED.v4n2.2017.74982

ISSN 2358-3932

\section{JULIÁN GONZÁLEZ GUYER}

Los Libros Blancos de Defensa, originados en Gran Bretaña y desarrollados desde los años 70' en el marco de los acuerdos de la Conferencia de Helsinki (CSCE-OSCE), ${ }^{1}$ llegaron a América Latina al finalizar de la guerra fría. El impulso provino de la Comisión de Seguridad Hemisférica de OEA que los propuso como una medida de fomento de la confianza mutua entre los países de la región, en marco de la reformulación del sistema de seguridad hemisférica. Sin embargo, las motivaciones para elaborar los pocos Libros Blancos de Defensa que han publicado los gobiernos sudamericanos, aparecen más vinculadas a objetivos de política domésticos que a razones de política exterior.

De inspiración político-filosófica y jurídica ajena a las tradiciones de la región, la primera generación de libros blancos de defensa - la ola hemisféri$c a$ - respondió en buena medida al impulso norteamericano en su búsqueda de adecuar el sistema de seguridad hemisférica a la nueva realidad de la implosión de la URSS y la desaparición del Pacto de Varsovia.

Dicho proceso de reformulación tuvo su primer hito formal con el Compromiso con la Democracia y la Renovación del Sistema Interamericano de Santiago de Chile en 1991, ${ }^{2}$ seguido - en 1994 - por la Cumbre de Presidentes de las Américas convocada por el Presidente George Bush (padre) en Miami, para desembocar al año siguiente en la primera Conferencia de Ministros de Defensa de las Américas, reunida a instancias del Secretario de Defensa de EEUU, William Perry en Williamsburg. La cuestión de los Libros Blancos de Defensa fue incluida en el programa de la Conferencia donde el marco de los intercambios referidos a la "Transparencia y Medidas de Construcción de Seguridad y Confianza Militar”, Canadá presentó un in-

Julián González Guyer - Dr. en Ciencia Política por la Universidad de la República (Uruguay) e investigador Nivel I del Sistema Nacional de Investigadores, Agencia Nacional de la Investigación e Innovación (Uruguay). 
forme sobre el proceso de elaboración de su, por entonces, recién publicado Libro Blanco. Fue el propio Perry quien resumió los debates con los célebres seis Principios de Williamsburg. ${ }^{3}$ El proceso de redefinición del sistema hemisférico de seguridad culminó recién en 2003, con la Conferencia Especial de Seguridad, convocada por OEA en México. Allí, los Cancilleres aprobaron una declaración de compromiso, consagrando las nueva - y variopinta - definición de seguridad hemisférica para la post-guerra fría.

Fue así que, sucesivamente, varios países latinoamericanos fueron publicando documentos de políticas de defensa. Un avance indudable respecto a la tradicional opacidad de los Ministerio de Defensa y de las instituciones militares de la región. Sin embargo, sus contenidos pusieron en evidencia las reticencias y debilidades de los Ministerios de Defensa. ${ }^{4}$ Además, pocos fueron los gobiernos que tomaron en cuenta la recomendación de instrumentar mecanismos reales y efectivos de consulta y participación para su elaboración.

Por su parte, el Consejo Suramericano de Defensa de Unasur ha optado por omitido este asunto y concentró sus esfuerzos del rubro medidas de confianza mutua en la elaboración del Registro Suramericano de Gastos de Defensa (RSGD) y del Registro Suramericano de Inventarios Militares (Resim) a través de su Centro de Estudios Estratégicos. ${ }^{5}$

$\mathrm{El}$ artículo sugiere algunas claves analíticas, ubicadas en el terreno de la cultura política, para comprender las dificultades de los países de la región para incorporar los Libros Blancos de Defensa como una práctica habitual. Concluye sugiriendo que, en última instancia, las explicaciones de su escasa difusión como instrumento de políticas, se relacionan con los bajos niveles de prioridad política de la defensa nacional y el escaso conocimiento e interés civil y político en estas cuestiones, tradicionalmente tramitadas lejos del escrutinio público. También que, habiendo sido introducidos en América Latina principalmente como instrumento asociado a la política exterior, su verdadera utilidad y sentido en Sudamérica parece vincularse principalmente a objetivos de política doméstica de los gobiernos.

En la primera parte del artículo se precisan los requisitos que debe cumplir un Libro Blanco de Defensa así como sus orígenes político-institucionales. Luego se examina cómo se implantaron en la región y cuál ha sido su evolución. Finalmente se exploran las razones de la mediocre performance de Sudamérica, a pesar de las recomendaciones de $\mathrm{OEA}^{6}$ y también de UNlirec.

\section{INTENTANDO DEFINIR LOS LIBROS BLANCOS DE DEFENSA ${ }^{7}$}

Hay que comenzar admitiendo que no es sencillo establecer una definición de libro blanco de defensa. Además, existe cierta propensión en la literatura a obviar una definición más o menos clara y ubicarlos en una 
difusa categoría que incluye a las Políticas de Defensa y las Estrategias de Defensa y/o de Seguridad Nacional. Ello contribuye a borrar sus especificidades e inclusive opacar su sentido.

En cambio, aquí se proponen una definición explícita y una descripción más o menos detallada de sus características, intentando además clarificar sus objetivos como instrumento de política pública.

En ausencia de una definición precisa y más o menos compartida universalmente, puede adoptarse la definición genérica de libro blanco que presenta el Parlamento británico; ${ }^{8}$ los libros blancos son documentos que dan cuenta de las políticas, planes y objetivos del gobierno respecto a un asunto. En ciertos casos, ellos preceden la presentación de una ley al Parlamento. Es frecuente en el Reino Unido que los Libros Blancos sean antecedidos por un Libro Verde, ${ }^{9}$ documento esencialmente tentativo, cuyo objetivo es promover un debate público que permita recoger puntos de vista para enriquecer el proceso de elaboración de una política o de una ley.

Así, desde el punto de vista de su origen, los libros blancos constituyen una práctica vinculada a la tradición política de Gran Bretaña y en general de los países anglo-sajones. De acuerdo a las fuentes consultadas, ${ }^{10}$ los libros blancos de defensa aparecen más tardíamente y se remontan a los finales de la década de los años 50’ del Siglo XX, también en Gran Bretaña.

El primer documento que podría calificarse como Libro Blanco de Defensa data de $1957^{11}$ y es interesante puntualizar que su publicación tuvo motivaciones de carácter doméstico. El hasta hoy polémico contenido del denominado Sandys White Paper, ${ }^{12}$ se vinculó a la necesidad de fundamentar ante la opinión pública y el propio establishment de la defensa, un drástico recorte del gasto militar en el marco del complejo desafío que Gran Bretaña enfrentaba para conciliar objetivos contradictorios (Taylor 2010, 3-5).

Por su parte, aunque no existe acuerdo entre los especialistas, podría establecerse que el primer Libro Blanco de Defensa de Canadá dataría de 1959, dos años después del británico. El siguiente vio la luz en $1964^{13}$ y la versión elaborada en $1994^{14}$ fue propuesta y adoptada como modelo por la OEA. Según el académico canadiense Douglas Bland, ${ }^{15}$ los Libros Blancos de Defensa de Canadá, no han sido documentos frecuentes y generalmente fueron piezas de la estrategia de algunos Ministros de Defensa decididos a implementar reformas contra la opinión mayoritaria del establishment militar.

Es obvio que la divulgación pública de las políticas de defensa nacional choca con ciertos hábitos institucionales de los Ministerios de Defensa y de las fuerzas armadas, instituciones habituadas tradicionalmente a la discreción y el secreto en el manejo de sus asuntos. 
Complementariamente a los países anglo-sajones y de forma paralela, en el marco de la Guerra Fría la $\operatorname{CSCE}^{16}$ fue adoptando iniciativas dirigidas a promover la confianza mutua y la cooperación entre los países de Otan y los del Pacto de Varsovia, con el fin de consolidar la détente y la paz frente a la amenaza de conflicto nuclear.

Fue de esa manera que, primero la Conferencia de Helsinki, devenida luego en Consejo para la Seguridad y Cooperación Europea (CSCE) y actualmente Organización (OSCE), promovió las denominadas medidas de confianza mutua como una de sus iniciativas que se extendieron y prolongaron en el tiempo. Así, junto a las diversas actividades de intercambio y conocimiento mutuo entre organizaciones militares, incluyendo operaciones combinadas, los países europeos comenzaron a incorporar la idea de que la difusión pública de sus capacidades bélicas podía contribuir a un mejor y más pacífico relacionamiento con sus vecinos y en particular con sus potenciales enemigos, evitando la dinámica asociada con lo que se conoce como el dilema de seguridad.

En particular, la llamada Comisión Palme planteó la idea de la seguridad común en 1982.

Ciertamente, este tipo de intercambios está siempre teñido de cierta duplicidad de intenciones. Instituidas formalmente como instrumentos de promoción de la amistad y la confianza mutuas e indudablemente efectivas en tal sentido, ellas poseen además un componente vinculado con las actividades de la inteligencia militar, interesada en conocer las capacidades y características de las demás fuerzas militares. También como instrumento de influencia política. Es interesante en tal sentido el concepto de lo que en EEUU se conoce como military to military contacts y que su Departamento de Defensa promueve y financia de manera activa. Incluso con potencias militares que percibe como rivales. ${ }^{17}$

En ese marco, aunque no exclusivamente, pueden ubicarse los libros blancos de defensa, asociados a la necesidad o conveniencia de explicitar las razones y los objetivos militares de los estados. Su diseminación en el mundo estuvo vinculada a la finalidad de fundamentar la postura estratégica y los planes de defensa de un estado, intentando evitar escaladas armamentísticas y posibles conflictos armados.

En la medida que la matriz político-institucional anglo-sajona de la que provienen los libros blancos, difiere de la tradición europeo-continental de la que son herederos los países de la región sudamericana, su adopción como práctica habitual en Sudamérica merece examen.

La monarquía en Inglaterra nunca fue absoluta; logró sobrevivir a la Revolución Gloriosa de 1689 al precio de aceptar las potestades del Parlamento, contenidas en el Bill of Rights. En cambio, en Europa con- 
tinental la caída del sistema monárquico, simbolizado en la Revolución Francesa, terminó con la restauración napoleónica; virtual secularización del absolutismo que tiñe aun las prácticas de gobierno, muy particularmente en Francia y la península ibérica, de cuyas tradiciones jurídico-políticas son herederos los países de América del Sur.

Así, el sistema jurídico en el Reino Unido se funda en los principios del derecho consuetudinario y las common laws mientras en Europa continental los sistemas jurídicos se construyeron sobre los cimientos del derecho romano.

Dicho basamento jurídico y político heredado por los países sudamericanos y asociado, por sus orígenes coloniales, a la Europa continental $\mathrm{y}$ al derecho romano se expresa en que nuestras autoridades de gobierno hablan a través de normas codificadas formalmente; leyes, decretos, resoluciones, etc. y además los hábitos políticos en Sudamérica no se adaptan fácilmente a las normas de transparencia y a la idea de accountability.

Así, a la luz de dichas diversidades de matriz político-cultural, no resulta llamativo constatar las dificultades de incorporar los libros blancos a las prácticas de administración de la defensa en Sudamérica. Una región donde además, los ejércitos jugaron un papel protagónico en la historia política de los distintos países, con la particularidad de haber asumido, en no pocos casos, el rol de gendarme lo que, en muchos casos, contribuyó a aislarlos de su propia sociedad.

De esta forma, la mayoría de los documentos que fueron publicando los Ministerios de Defensa de la región a partir de fines de los 90', ${ }^{18}$ explicitaron en diferentes grados sus políticas de defensa nacional y divulgaron información acerca de sus fuerzas armadas - con variada trasparencia y detalle -, sin embargo pocos podrían considerarse stricto sensu como libros blancos de defensa.

En efecto, tomando como referencia las recomendaciones de organismos internacionales como la Comisión de Seguridad Hemisférica de OEA (CSH) y UNlirec, ${ }^{19}$ los libros blancos de defensa para ser considerados como tales, deben cumplir con ciertos requisitos sustantivos y procedimentales. Los primeros refieren a la calidad de sus contenidos - una clara y fundamentada exposición de las políticas de defensa, sus objetivos y planes, así como las capacidades militares y la postura estratégica del país -, mientras los segundos tienen que ver con los procesos de consulta y negociación cumplidos para su elaboración.

El perfeccionamiento de los contenidos de los Libros Bancos de Defensa puede vincularse a su papel como instrumento de promoción de la confianza mutua. Sin embargo, un documento claramente formulado y fundamentado, también potencia su utilidad en lo doméstico, como guía orientadora 
para las diferentes agencias vinculadas a la defensa y por su significación como compromiso político ante la oposición política y la ciudadanía.

Por otra parte, la transparencia y la amplia participación social y política en su elaboración pueden asociarse al objetivo de perfeccionar las relaciones entre la sociedad y las fuerzas armadas en el marco de las políticas de reforma democrática del sector defensa. En efecto, los procesos participativos, si son adecuadamente concebidos, generan canales de comunicación más fluidos entre militares y civiles, contribuyendo a dotar de mayor legitimidad a las políticas del Ministerio de Defensa y a promover un mayor conocimiento e interés del sistema político y la sociedad civil respecto de una temática con la que generalmente han tenido escasos vínculos e incidencia.

Desde el punto de vista de su contenido, son documentos de gobierno donde se fijan los principales lineamientos y objetivos de sus políticas de defensa, explicitan la postura estratégica del país, detallando sus capacidades militares y los planes futuros de su desarrollo.

Pero además, dichos contenidos deben reflejar ciertos niveles de consenso político y social. De allí que adquieren relevancia los aspectos procedimentales de su elaboración. Ello también se vincula, como se verá después, a la legitimidad y durabilidad de las políticas y planes de defensa, que constituyen dos de sus rasgos necesarios.

El criterio adoptado aquí para establecer si un documento gubernamental es efectivamente un libro blanco de defensa se apoya de forma genérica en el documento "Lineamientos para la Elaboración de Documentos sobre Políticas y Doctrinas Nacionales de Defensa" ${ }^{20}$ (a partir de aquí LEDPND), elaborado por la CSH y aprobado por el Consejo Permanente de la Organización, ${ }^{21}$ el cual por otra parte es coherente con las definiciones vistas más arriba.

Evaluados según dicho rasero, son pocos los documentos sobre políticas de defensa publicados en Sudamérica que logran superar el cotejo con los lineamientos sugeridos en el documento de la CSH.

En efecto, es posible diferenciar dos dimensiones analíticas que definen los requisitos para que un documento, publicado por el Ministerio de Defensa de un país, califique como libro blanco de defensa; una dimensión procedimental referida a los mecanismos de consulta implementados para su elaboración y una dimensión sustantiva que refiere a sus contenidos. A cada una de ellas, el LEDPND dedica un capítulo.

Los requerimientos de la dimensión procedimental pueden resumirse en la recomendación de que el Ministerio de Defensa, organismo de gobierno responsable principal de su elaboración, deberá asegurar que ella contemple los mecanismo más amplios de consulta posible. 
Los procesos de participación y consulta incluyen a actores gubernamentales y no gubernamentales. En el primero de los ámbitos sugiere, junto a los organismos del propio Ministerio de Defensa y a las jerarquías superiores de las Fuerzas Armadas, ${ }^{22}$ la necesaria participación de otros Ministerios, particularmente el de Relaciones Exteriores, así como de las agencias responsables del presupuesto, al igual que los gobiernos sub-nacionales y el Parlamento; sus Comisiones de Defensa y los legisladores de la oposición.

La segunda categoría de actores, refiere a la sociedad civil. Menciona particularmente entre los protagonistas clave a ser consultados: las organizaciones no gubernamentales, la academia, las empresas privadas y hasta lo que denomina los grupos de estudio y una categoría que define como los asociados internacionales (sic).

El LEDPND precisa que, de todas formas, la celebración de consultas y la implementación de mecanismos de participación, no excluye que el libro blanco refleje las orientaciones del Ministerio de Defensa, al que asigna un papel cardinal en la elaboración de la concepción y el temario de defensa.

La segunda dimensión de los requerimientos de un libro blanco de defensa; definida aquí como sustantiva, es objeto de un inventario descriptivo en el LEDPND que los caracteriza como sus componentes habituales. Dicha enumeración se presenta bajo la forma de una sugerencia respecto a cómo organizar el documento. Sintéticamente, dicho catálogo incluye: política y doctrina de defensa (entorno interno y externo, postura estratégica, amenazas percibidas, misiones de las fuerzas armadas), capacidades militares presentes y programadas, asuntos presupuestales y recursos, orientaciones militares futuras (modernización, reformas, compras militares significativas) y estructura militar de la defensa.

En resumen, como señala el LEDPND; las orientaciones del Ministerio de Defensa se apoyarán en las definiciones del Gobierno sobre el entorno estratégico, las necesidades de defensa del país, las finalidades y prioridades del Gobierno y los recursos disponibles.

Establecidos los criterios que permiten diferenciar un Libro Blanco de Defensa de un simple documento de políticas de defensa o de un documento de estrategia de defensa nacional, es posible ensayar sintéticamente un análisis del estado del arte del tema en Sudamérica.

Previamente es necesario detenerse para establecer sintéticamente que si bien un libro blanco de defensa debe explicitar tanto la política como la estrategia de defensa de un país, se diferencia de otros documentos por dos rasgos fundamentales; debe transparentar sus capacidades militares actuales y las que se planifican en un futuro previsible, además de expresar acuerdos construidos en procesos de consulta y debate informado razona- 
blemente amplios, a iniciativa y bajo la dirección del Ministerio de Defensa. Esto es, el libro blanco de defensa debe reflejar la política que efectivamente impulsa el gobierno y al mismo tiempo contar con el mayor grado de acuerdo político y social.

\section{LIBROS BLANCOS DE DEFENSA; SU INTRODUCCIÓN E INSERCIÓN EN AMÉRICA LATINA}

En realidad, el trayecto histórico de los libros blancos de defensa hasta su llegada a América Latina para llegar al período de su implementación en América del Sur, muestra que el uso de este tipo de documento, de hecho, puede responder a diversas lógicas, adaptándose o sirviendo a diferentes motivaciones de los gobiernos. Así lo muestra, por ejemplo, el caso de Canadá citado más arriba

El primer Libro Blanco de Defensa en América del Sur fue publicado en 1997 por la administración del Presidente chileno, Eduardo Frei. Con el telón de fondo de la normalización de relaciones con Argentina (Runza 2004) y de cierta inquietud regional generada por las inversiones militares chilenas $^{23}$, aquella primera experiencia tuvo también entre sus objetivos contribuir a desarrollar una "comunidad de defensa" en el país (Barrachina 2008, 30-31, Soto Silva 2016). De hecho, el Libro de Defensa de Chile de 1997 apareció en el marco general de una mayor apertura del sector de la defensa en el conjunto de la región, no sólo fronteras afuera, sino en su relación con la sociedad civil de cada país.

Originalmente, en los años 90', al finalizar de la Guerra Fría, la Comisión de Seguridad Hemisférica de OEA (CSH) promovió los libros blancos de defensa como una medida de transparencia dirigida principalmente a fomentar la confianza mutua entre países de la región. Fue en $2002^{24}$ que su Consejo Permanente formuló una recomendación concreta en respuesta a la resolución de la Asamblea General referida al "Fomento de la Confianza y la Seguridad en las Américas". ${ }^{25}$ El documento con recomendaciones para la elaboración de Libros Blancos de Defensa que emitió la CSH tuvo como base una propuesta canadiense ${ }^{26}$. Unos años después también UNlirec presentó su guía metodológica estándar. ${ }^{27}$

Por su parte, la Junta Interamericana de Defensa (JID), luego que su estatus en relación a la OEA fuera finalmente regularizado en 2006, se ha erigido en el organismo hemisférico más activamente involucrado en la promoción y el seguimiento de los Libros Blancos de Defensa, ofreciendo asesoramiento técnico a los gobiernos latinoamericanos y del Caribe sobre la cuestión. ${ }^{28}$ 
Es sintomático, por otra parte, que en la región sólo se hayan publicado libros blancos de defensa y que no existan antecedentes de documentos de este tipo referidos a otras áreas de políticas públicas.

La CSH, a pesar de haber elaborado lineamientos para su elaboración, al resumir la situación en la región, opta por el concepto laxo y políticamente neutro ${ }^{29}$ de documentos de políticas de defensa incluyendo en su catálogo, junto a los libros blancos de defensa, a una serie de otro tipo de documentos como, por ejemplo, la Estrategia de Seguridad Nacional de EEUU.

Parece ineludible señalar que el Consejo Suramericano de Defensa de Unasur (CDS) y su Centro de Estudios Estratégicos (CEE) han preferido eludir los Libros Blancos de Defensa y en cambio dirijan su esfuerzo en el plano de las medidas de confianza mutua hacia el intercambio de información de políticas de defensa, de presupuesto, de organización, de estructuras de ministerio (habiendo) logrado institucionalizar, cuando menos, ya dos instrumentos: el Registro Suramericano de Gastos de Defensa y el Inventario Militar Suramericano (Celi 2014, 5). ${ }^{30}$

Dicho trabajo,

[...] muy avanzado en su elaboración, ha visto trabada su divulgación principalmente por la reticencia del gobierno de Colombia que, por otra parte, ha instalado un Centro Regional de Estudios Estratégicos (CREES), con financiamiento norteamericano, en evidente competencia con la iniciativa de crear la Escuela de Defensa Sudamericana (Celi 2014, 5). ${ }^{31}$

De todas maneras, el CEE del CDS ha editado ya varias versiones del Registro Suramericano de Gastos Agregados en Defensa; 2006-2010 en diciembre de 2014, ${ }^{32} 2011-2013$ en mayo de $2016^{33}$ y finalmente en enero de 2017 una edición especial que reúne toda la información de la década 2006-2015. ${ }^{34}$

Previo a revisar con mayor detalle el comportamiento de los países de América del Sur ante la sugerencia realizada por la OEA en 2002, conviene profundizar en las razones que explican la importancia de los procesos de consulta en la elaboración del libro blanco de defensa y contribuyen a dotarlo de alguna de sus especificidades, al mismo tiempo que lo diferencian de otro tipo de documentos, como por ejemplo los de Política de Defensa o de Estrategia de Defensa o Seguridad Nacional, etc.

En efecto, la subsidiariedad de las políticas de defensa nacional respecto a la política exterior de un estado, junto a sus inevitablemente largos períodos de maduración, vuelven altamente deseable la construcción de acuerdos políticos y sociales amplios en esta arena de políticas. Un mecanismo 
que permite evitar el riesgo asociado a las denominadas políticas de estado, definidas como aquellas que trascienden los vaivenes naturales de la democracia con su natural rotación de partidos y orientaciones políticas en el ejercicio del gobierno y cuya importancia es generalmente mistificada por las visiones tecnocráticas que tienden a sustraerlas del debate público democrático.

El marco ordenador de las necesidades de un estado en el plano de su defensa resulta básicamente de su estrategia general de desarrollo y de su postura estratégica internacional; las características de sus relaciones exteriores; las alianzas, tratados y acuerdos que definen su inserción externa y su ubicación en el sistema de relaciones de poder internacional. Sobre dicha base y en términos democráticos ideales, la sociedad y el sistema político que la representa, determinan el nivel de esfuerzo presupuestario a dedicar a esta política pública. Los gobiernos determinan la estrategia y las capacidades requeridas por el aparato de defensa nacional; planifican el tipo de estructura de fuerzas armadas y su despliegue, definen las características de sus instituciones militares y de su personal profesional, establecen los sistemas de armas con los que dotarlas, así como la eventual participación de la ciudadanía en la defensa.

Los procesos de adquisición y/o de desarrollo de los sistemas de armas (último eslabón del proceso de decisiones y a su vez factor determinante del tipo de formación de los recursos humanos necesarios), al igual que las adecuaciones y reformas de las instituciones armadas, son procesos complejos y largos. Por tanto, no resulta aconsejable que la planificación de la defensa nacional quede sujeta a cambios significativos en períodos cortos de tiempo.

Las complejidades e implicancias de la planificación de la defensa nacional han conducido tradicionalmente al atajo de sustraerla de la consideración y el debate públicos para ponerla en manos de tecnocracias especializadas y/o élites políticas supuestamente iluminadas. Con la justificación de su sofisticación técnica y gran sensibilidad política, diplomáticos y militares; las dos burocracias profesionales del estado involucradas en el tema y ambas herederas de una larga tradición con raíces en los hábitos de la aristocracia cortesana del Siglo XVII (Guzzini 2013, 525-526), ${ }^{35}$ tienden a mantener los procesos de decisión sobre estas materias alejados del escrutinio público. Sin embargo, se obvia que la defensa constituye un área de políticas de alta sensibilidad democrática pues involucra asuntos muy trascendentes para el conjunto de la sociedad y además compromete la inversión de recursos financieros y humanos significativos en horizontes largos de tiempo.

En cambio, la solución para esta aparente paradoja es la construcción de los consensos más amplios y más democráticamente construidos que 
sea posible. De allí la importancia de la dimensión procedimental en relación con el diseño de los procesos participativos en la elaboración de los Libros Blancos de Defensa.

Para el caso de los países sudamericanos deben agregarse dos argumentos no desdeñables que refuerzan la relevancia de la dimensión procedimental. En primer lugar, al promover la inclusión de la mayor cantidad de sectores políticos y actores sociales en la construcción de políticas de defensa nacional se contribuye simultáneamente a promover un mayor involucramiento social en estas cuestiones y a modificar arraigadas tradiciones institucionales en las fuerzas armadas acerca de su papel tutelar y de su condición de reserva moral y custodia de valores eternos que supuestamente definen la patria y la nacionalidad. Por otra parte, cuando es necesario implementar cambios en el sector de la defensa, la construcción de coincidencias y acuerdos entre los principales actores políticos y sociales facilita su aceptación por parte de las fuerzas armadas.

\section{LIBROS BLANCOS EN SUDAMÉRICA; EL ESTADO DEL ARTE}

Debe establecerse que no es sencillo elaborar un repertorio actualizado y detallado de los Libros de Defensa publicados en Sudamérica. Y ello por dos razones. La primera, como se desprende de todo lo establecido hasta aquí, deriva de la ausencia de acuerdo entre los diversos autores y fuentes consultadas para definir inequívocamente estos documentos. La segunda es que en la revisión realizada no se ubicó ningún trabajo académico más o menos aceptado, que establezca cuáles son los documentos sobre políticas de defensa nacional que cumplen con los requisitos necesarios para ser definidos como libros blancos de defensa.

En efecto, las dos referencias regionales son la $\mathrm{CSH}$, cuya página web incluye un listado de lo que denomina documentos de políticas defensa (Libros Blancos) en las Américas ${ }^{36}$ y un mapa interactivo en la página web del Ministerio de Defensa de Argentina que presentaba referencias de la región y el mundo, pero ya no se encuentra disponible.

Como ya se adelantó, la historia de los libros blancos de defensa en Sudamérica fue abierta por una publicación del gobierno chileno en 1997 y al iniciarse 2017 los dos mayores países de la región -Argentina y Brasil -, han presentado recientes versiones de sus libros blancos de defensa, ${ }^{37}$ mientras el Ministerio de Defensa de Chile ha dado señales de estar planificando una nueva revisión de su denominado Libro de Defensa. En el caso argentino se trata del tercero, al igual que Brasil, mientras que, en cambio, el chileno sería el cuarto. La sincronía entre Brasil y Argentina ambientó incluso que las autoridades brasileñas invitaran al Ministerio de Defensa 
de Argentina a participar de un taller en la Escuela de Superior Guerra, Río de Janeiro, en el marco de su elaboración. ${ }^{38}$

El Ministro de Defensa de Chile, Jorge Burgos, en el marco de su vista a Buenos Aires, para el lanzamiento del proceso de elaboración del Libro Blanco de Defensa de Argentina, quien anunció la voluntad del nuevo gobierno chileno de la Presidenta Michelle Bachelet de realizar una actualización de su Libro de Defensa. ${ }^{39}$

A los efectos de un análisis comparado de la performance de los diferentes países de la región durante el período 1997-2017 se elaboró una Tabla, que se presenta más abajo, en la que se sintetiza la información de la Comisión Hemisférica de Seguridad (DCSH) de OEA, ${ }^{40}$ actualizada por el autor. Se optó por mantener el criterio de la CSH de incluir también otros documentos de políticas de defensa que no pueden ser definidos como Libros Blancos, ya sea por sus contenidos o por razones de tipo procedimental. ${ }^{41}$

En un primer análisis general de la Tabla adjunta, resulta que los países sudamericanos más prolíficos en la publicación de documentos de políticas de defensa son Argentina, Brasil, Ecuador y Chile.

En el otro extremo del ranking sudamericano, debe ubicarse a Venezuela que no ha publicado ningún documento de política de defensa en las últimas dos décadas.

Un segundo nivel de análisis supone discriminar, entre el conjunto de documentos publicados por los países sudamericanos incluidos en la Tabla, para señalar cuáles son pueden ser definidos como Libro Blancos de Defensa. Los criterios para ello -contenidos sustantivos y mínimos estándares de carácter procedimental - ya fueron explicitados más arriba. Una vez conformado dicho universo de casos será posible proponer algunas conclusiones respecto a las razones que pudieran haber impulsado a los gobiernos a elaborar Libros Blancos de Defensa o por el contrario optar por otras alternativas, inclusive no divulgar información. 


\section{LIBROS BLANCOS Y OTROS DOCUMENTOS DE DEFENSA} EN AMÉRICA DEL SUR - Un Resumen Sinóptico

\begin{tabular}{|l|l|c|}
\hline País & Título & Año \\
\hline Argentina & Libro Blanco de la República Argentina & 1999 \\
& & $2010^{1}$ \\
& & 2015 \\
\hline Bolivia & Libro Blanco de Defensa Bolivia & $2004^{10}$ \\
\hline Brasil & Política de Defensa Nacional & 1996 \\
& Política de Defensa & 2005 \\
& Estrategia Nacional de Defensa & $2008^{2}$ \\
& Libro Blanco de Defensa & $2012^{3}$ \\
& Libro Blanco de Defensa & 2017 \\
\hline Chile & Libro de la Defensa Nacional de Chile & $1997^{4}$ \\
& & $2002^{5}$ \\
& & $2010^{5}$ \\
\hline Colombia & Políticas de Defensa y Seguridad Democrática & $2003^{13}$ \\
& Políticas de Defensa y Seguridad para la Nueva Colombia, 2015-2018 & $2015^{14}$ \\
\hline Ecuador & Libro Blanco de la Defensa Nacional & 2002 \\
& Libro Banco de Defensa & 2006 \\
& Hacia una Nueva Política de Seguridad Interna y Externa & $2008^{6}$ \\
& Agenda Política de Defensa & 2011 \\
& Agenda Política de la Defensa 2014-2017 & $2014^{12}$ \\
\hline Paraguay & Plan Global del MDN ${ }^{10}$ y Política de Defensa Nacional ${ }^{11}$ & 1999 \\
\hline Perú & Libro Blanco de la Defensa Nacional del Perú & $2005^{7}$ \\
\hline Surinam & Plan Anual del Ministerio de Defensa & 2012 \\
\hline Uruguay & Bases para una Política de Defensa Nacional & 1999 \\
& La Defensa Nacional, Bases para un Debate & $2005^{8}$ \\
& Política de Defensa Nacional & $2014^{9}$ \\
\hline
\end{tabular}

Fuente: elaborado por el autor a partir de la CSH (http://www.oas.org/CSH/spanish/ doclibrdef.asp), el Ministerio de

Defensa de Argentina (<http://www.libroblanco.mindef.gov.ar/>) y otras fuentes que se detallan:

\section{Referencias}

${ }^{1}$ Disponible en <http://www.ceedcds.org.ar/Srd-LibBL/ARG/Libro_Blanco_Argentina. pdf>.

${ }^{2}$ Disponible en <http://www.planalto.gov.br/ccivil_03/_ato2007-2010/2008/Decreto/ D6703.htm>.

${ }^{3}$ Disponible en <http://www.defesa.gov.br/arquivos/2012/mes07/lbdn.pdf $>$.

${ }^{4}$ Disponible en <http://www.defesa.gov.br/arquivos/2012/mes07/lbdn.pdf $>$.

${ }^{5}$ Disponible en <http://www.ssffaa.cl/libro-de-la-defensa-nacional-de-chile-2002/>.

${ }^{6}$ Disponible en <http://scm.oas.org/pdfs/2012/cshecuadorlibrosblancos.pdf $>$.

${ }^{7}$ Disponible en <http://www.mindef.gob.pe/vercontenido.php? $\operatorname{archivo=menu/libroblan-}$ co/index.htm $>$.

${ }^{8}$ Publicado en papel por la Oficina de RR.PP. del Ministerio de Defensa Nacional con fecha enero de 2005. No se encuentra en internet. 
${ }^{9}$ Disponible en <http://www.calen.edu.uy/noticias/2014/05_mayo/pdf/Politica-de-DefensaNacional-CODENA-Uruguay-2014.pdf $>$.

${ }^{10}$ Disponible en <http://www.oas.org/CSH/spanish/doclibrdef.asp>.

${ }^{11}$ Disponible en < http://www.libroblanco.mindef.gov.ar/countries/libros/Doc-Paraguay-1999. pdf $>$ (ya no se encuentra accesible)

${ }^{12}$ Disponible en <http://www.defensa.gob.ec/wp-content/uploads/downloads/2014/o6/ Agenda-Politica-Defensa.pdf $>$.

${ }^{13}$ Disponible en <http://www.oas.org/csh/spanish/documentos/Colombia.pdf>.

${ }^{14}$ Disponible en <https://www.fac.mil.co/sites/default/files/politica_defensa_para_la_ nueva_colombia_2015-2018.pdf >. Acceso en 18 jun. 2017.

Conviene comenzar por los cuatros países que mayor número de documentos han publicado. Es interesante el caso de Ecuador, con cinco documentos elaborados y difundidos durante el período considerado.

Desde el punto de vista procedimental, los procesos de consulta instrumentados por los distintos gobiernos ecuatorianos para la elaboración de sus documentos de política de defensa presentaron grados de amplitud dispares desde el punto de vista de los actores consultados y de los mecanismos de participación instrumentados. Los dos primeros (2002 y 2006), ambos financiados por EEUU, ${ }^{42}$ tuvieron procesos muy restringidos de consulta (García Gallegos 2008, 461).

En 2008, un año después de la primera elección del Presidente Rafael Correa, fue divulgado un nuevo documento que plasmó las nuevas concepciones que a partir de entonces han caracterizado la doctrina de defensa de Ecuador. El mismo fue seguido de otros dos; en 2011 y 2014. En todos los casos, estos tres últimos documentos, contemplaron ciertos mecanismos de consulta durante su elaboración, principalmente el primero de ellos.

En cambio, desde el punto de vista sustantivo, resulta llamativo que ninguno de los cinco documentos publicados haya transparentado las capacidades militares reales de las Fuerzas Armadas ecuatorianas; además el único Libro Blanco de Defensa que incluyó alguna información presupuestal fue el primero (2002). La omisión de un requerimiento sustantivo de tal significación impide que sus denominados Libros Blancos de Defensa puedan considerarse tales.

La permanencia de tales rasgos, trascendiendo incluso los significativos cambios de orientación política de su gobierno, obliga a dirigir la atención hacia variables explicativas de carácter estructural, lo que conduce a dos hipótesis complementarias. La primera de ellas refiere a las conflictivas relaciones de Ecuador con dos de sus vecinos; Perú y Colombia. En el primer caso, el no tan lejano enfrentamiento armado de 1995, dejó ciertas secuelas no resueltas, mientras que en el segundo, diversas consecuencias del desborde del conflicto interno colombiano en la zona fronteriza ecuatoriano 
han enrarecido una relación históricamente compleja. La segunda hipótesis explicativa refiere a la influencia política que conservan las instituciones militares en los procesos políticos de Ecuador y como consecuencia el peso que ellas han ejercido en la determinación de los contenidos de los Libros Blancos publicados.

Hechas estas precisiones respecto a Ecuador, los otros tres países de la región que ha publicado documentos de políticas de defensa más asiduamente son Argentina, Brasil y Chile. En los tres casos, desde el punto de vista de sus contenidos y de los procedimientos elegidos para su elaboración, puede aceptarse que ellos se aproximan razonablemente a la definición de Libro Blanco de Defensa. En efecto, una evaluación genérica, permite aventurar que los documentos atienden las definiciones y la información requerida y que de alguna forma implementaron mínimos mecanismos consulta en su elaboración. Sus déficits, tanto sustantivos como procedimentales, pueden considerarse como expresiones de las dificultades que enfrentan este tipo de procesos inéditos en la región que suponen modificar tradiciones muy arraigadas en los gobiernos - Poder Ejecutivo y Legislativo -, los Ministerios de Defensa y las Fuerzas Armadas e incluso en la sociedad civil de los países sudamericanos.

Chile, el país que inauguró la política de elaboración de Libros Blancos de Defensa en la región, con la publicación del denominado "Libro de la Defensa Nacional” en 1997, al que siguieron las revisiones de 2002 y 2010 , ha exhibido un nivel comparativamente bueno, desde el punto de vista de los requerimientos para este tipo documentos. La publicación de los Libros de Defensa por parte del gobierno chileno debe ubicarse en el contexto de dos procesos paralelos e interconectados en el marco de la normalización institucional del período post-pinochetista.

Por una parte, el proceso de normalización de sus tradicionalmente conflictivas relaciones vecinales y por otra la construcción de relaciones civiles militares ajustadas a los estándares democráticos.

En el plano de las relaciones con los países vecinos, el desarrollo del poderío militar de las Fuerzas Armadas chilenas ${ }^{43}$ generó desconfianza en ciertos sectores castrenses y civiles de los otros países de la región, proporcionando argumentos a sectores interesados en el fomento del armamentismo. ${ }^{44}$ Dotado de las FFAA más modernas de Sudamérica y con un nivel de inversión en equipamiento militar que contrasta con la realidad general de la región, Chile ha ido parsimoniosamente resolviendo los conflictos limítrofes con sus tres países vecinos desde fines de los años 70', cuando llegó al borde de la guerra con Argentina. Actualmente, ya solucionados los contenciosos más graves con Buenos Aires y luego del fallo de la Corte de Justicia de La Haya que laudó la controversia sobre límites 
marítimos con Perú en 2014, resta resolver la más compleja cuestión del reclamo boliviano de salida al mar.

Entre tanto en el plano doméstico, a partir de 1990, Chile ha ido avanzando en el proceso de normalización democrática de sus relaciones civiles-militares, en el marco de una transición fuertemente condicionada por la Constitución heredada del régimen del Gral. Augusto Pinochet. En efecto, como se adelantó más arriba, una de las motivaciones de los gobiernos chilenos al impulsar la elaboración de los Libros de Defensa se vincularon a la promoción de una comunidad de expertos civiles en asuntos de defensa. En este sentido, podría señalarse que Chile constituyó unos de primeros países de Sudamérica en los que, hacia fines de los años 90', se generó cierta masa crítica de académicos y expertos civiles en estos temas. Un fenómeno que sin embargo no tuvo continuidad hasta el presente.

Podría agregarse un apunte referido al caso chileno, pero de validez y significación más general. Como señalan García y Montes (2009, 82 $)^{45}$ los procesos de intercambio y debate entre las jerarquías militares y los responsables políticos de la defensa, además de académicos y otros actores civiles, durante la elaboración de los dos primeros Libros de Defensa de Chile, jugaron un papel significativo en la modernización democrática del sector. Dicha experiencia permite poner de relieve la relevancia del adecuado diseño del proceso de elaboración de estos documentos. Ello permite mejorar, no sólo los contenidos del Libro Blanco ${ }^{46}$ sino, principalmente contribuir al funcionamiento democrático del sector defensa. En efecto, ello no sólo genera condiciones para el diálogo franco entre jerarquías militares, burocracias civiles y responsables y asesores políticos del Ministerio de Defensa. También promueve el desarrollo de una comunidad académica especializada.

Sin embargo, mirado el proceso, desde la perspectiva de 2017 , destaca la cuasi-extinción de la otrora relativamente numerosa y activa comunidad académica de estudios de defensa chilena. Ello pone de relieve la necesidad de esfuerzos sostenidos que eviten procesos de des-acumulación como el vivido por Chile en los últimos años.

Así, podría concluirse que una verdadera constelación de motivaciones, tanto de política exterior como de política doméstica, contribuye a explicar tanto la periodicidad con que Chile ha revisado su Libro de Defensa como la preocupación de su Ministerio de Defensa en observar los requisitos de sus dos dimensiones; sustantiva y procedimental.

Argentina, por su parte, el país sudamericano que más ha avanzado en el proceso de fortalecimiento del componente civil/político al interior del Ministerio de Defensa, ha actualizado periódicamente el Libro Blanco de Defensa, cuyos contenidos y procedimientos de elaboración, 
se acercan a los requerimientos del LEDPND. Debe señalarse de todas formas, desde el punto de vista de los actores involucrados en el proceso de elaboración, que la inclusión de actores no gubernamentales no ha logrado avanzar mucho más allá de algunas Universidades y unas pocas organizaciones no gubernamentales ${ }^{47}$. Además, la consulta a otros ministerios y a gobiernos sub-nacionales parece haber sido muy limitada. La periodicidad con la que el Ministerio de Defensa argentino ha actualizado el libro blanco resulta coherente con proceso de fortalecimiento de las capacidades y las prerrogativas civiles en la conducción político-estratégica de la defensa.

Por otra parte, la coincidencia temporal del Libro Blanco de Defensa de Argentina (1999) con el que publicó Chile (1997) también es llamativa. En efecto, si bien las fuerzas armadas argentinas difícilmente podían generar intranquilidad en su vecino trasandino, visto el progresivo de sus capacidades operativas a partir la salida del régimen autoritario en 1983, parece posible asignar al Libro Blanco argentino de 1999 el carácter de medida espejo, incluso si su significación real fuera en realidad cuasi-simbólica. Ello parece coherente con la voluntad recíproca de Buenos Aires y Santiago de Chile de sanear sus relaciones militares, claramente expresada en el proceso del COMPERSEG, ${ }^{48}$ iniciado en 1995 y que en agosto de 2016 ya había celebrado su XXVIII Reunión de Consulta. ${ }^{49}$

En cuanto a Brasil, debe precisarse que es el único país sudamericano con una que ley obliga al Ministerio de Defensa a presentar al Congreso una revisión actualizada del Libro Blanco de Defensa cada cuatro años (a partir de 2012). Además, el mismo debe estar acompañado de otros dos documentos relevantes: la Política de Defensa y la Estrategia de Nacional de Defensa. ${ }^{50}$ La Ley establece explícitamente que la Estrategia Nacional de Defensa debe servir para la presupuestación y el planeamiento anual del sector. La Ley detalla además de forma preceptiva cuáles deben ser son los contenidos del Libro Blanco.

En efecto, éste deberá brindar información detallada sobre estrategia, presupuesto, asuntos institucionales y materiales de las fuerzas armadas, precisando los ocho capítulos que deben organizarlo. De tal forma, los contenidos del Libro Blanco de Brasil permiten calificarlo como tal, con la precisión de que los procesos de consulta implementados en su elaboración han sido limitados, contemplando sólo a un cierto número de académicos y algunos notorios diplomáticos y altos oficiales militares en retiro. De todas formas, puede anotarse que los procesos de consulta, principalmente a sectores académicos, han ido perfeccionándose. Ciertamente, en este fenómeno ha incidido la vitalidad que exhibe la Asociación Brasileña de Estudios de Defensa (ABED). 
Vale la pena señalar que Brasil es un caso notable por la coexistencia de dos fenómenos contradictorios. Por una parte, la muy significativa influencia política de sus establishments militar y el diplomático; dos burocracias estatales preeminentes de indudable prosapia imperial. Ambas constituyen actores muy significativos en la determinación de las líneas estratégicas del gigante sudamericano y ello no podría dejar de reflejarse en la metodología de elaboración de sus Libros Blancos de Defensa. El segundo fenómeno - único en la región - es el fuerte dinamismo desarrollado desde por la comunidad académica brasileña vinculada a la defensa nacional, las relaciones internacionales y los asuntos estratégicos. En efecto, a impulsos de la $\mathrm{CNPq}^{51}$ y con significativo apoyo del Ministerio de Defensa, la Asociación Brasilera de Estudios de Defensa (ABED) ha ido nucleando un importante número de académicos civiles - también militares - lo cual, en condiciones políticas normales, ${ }^{52}$ permitiría prever que el proceso de revisión parlamentaria del Libro Blanco de Defensa 2017, sea acompañado de mayores niveles de consulta y participación.

La emergencia algo tardía de Brasil como uno de los países que publican y revisan periódicamente su libro blanco de defensa aparece asociada con la estrategia impulsada por el Presidente Lula Da Silva de proyectar internacionalmente a su país al nivel de las potencias emergentes y para ello priorizar América del Sur como su espacio de asociación estratégica básica. Ambas dimensiones de su estrategia de política exterior suponen la necesidad de transparentar las capacidades militares y de explicitar la postura estratégica de Brasil en relación al mundo y en particular a sus países vecinos de América del Sur. En el plano doméstico, los documentos elaborados por el Ministerio de Defensa de Brasil, con especial claridad la Estrategia Nacional de Defensa 2008, enfatizan el vínculo de la defensa con la democracia, el desarrollo y el bienestar social.

Así, puede concluirse que la incorporación de Brasil al selecto grupo de países sudamericanos que adoptaron la práctica de publicar y revisar periódicamente su libro blanco de defensa responde a una lógica diferente. Ella refleja la singular estatura estratégica brasileña en relación al resto de los países de la región pero también la voluntad política de un gobierno de asumirla a plenitud.

De cualquier forma, debe precisarse que la obligación legal de revisar cuatrienalmente sus documentos de defensa que rige en Brasil, plantea el riesgo de banalización que corre cualquier proceso que se convierte en rutina burocrática. En tal sentido, debe señalarse que los documentos de defensa enviados por el Ministerio de Defensa al Congreso, a fines de $2016,{ }^{53}$ ingresaron para su consideración parlamentaria sin que hubieran sido aprobados los documentos elevados en 2012. 
Conviene detenerse brevemente en Perú. El proceso de publicación de su único libro blanco de defensa resultó largo y complejo; estuvo perlado por diversas idas y venidas desde que un primer texto fuera elaborado por Oficiales militares en 1998. La saga incluyó cinco versiones provisorias; la primera durante el gobierno del Presidente Fujimori, la segunda durante el interinato de Valentín Paniagua y las últimas tres a lo largo del mandato del Presidente Toledo. Fue en dicho último período que se verificó un proceso más o menos abierto de consultas. A partir de la cuarta versión y redactado por funcionarios del Ministerio de Defensa, se llegó en 2005 al documento definitivo (Barrachina 2008, 433-434). Desde entonces, Perú no volvió a revisar su Libro Blanco de Defensa.

En cuanto a las motivaciones que pudieran haber impulsado al gobierno a elaborar su Libro Blanco de Defensa entre 1998 y 2005 y visto el sincronismo entre el inicio del proceso de elaboración en Perú y la publicación del primer Libro de la Defensa de Chile, podría hipotetizarse que una motivación significativa para su impulso inicial pudo estar vinculada con el conflicto limítrofe que Perú y mantenía con su vecino meridional.

A continuación se presenta una revisión sintética del resto de los países de la región.

Bolivia sólo elaboró un documento de política de defensa que, sin embargo, no podría asimilarse a un libro blanco por la ausencia de procesos de consulta abiertos en su elaboración y también por su tardía difusión pública. En efecto, el denominado Libro Blanco de Defensa de Bolivia, elaborado en 2004, sólo fue divulgado una década después. ${ }^{54}$ En 2007 el autor pudo verificar que no se encontraba disponible (González Guyer 2008, 478) y tres años después la situación se mantenía (González Guyer 2010, 9). Sin embargo, hacia fines de 2014, cuando el autor actualizó la información para un documento presentado en Río Janeiro (González Guyer 2014, inédito), encontró que el documento había sido incluido en la página web de la CSH de OEA. ${ }^{55}$ Este particular recorrido parece asociado al proceso que culminó con la renuncia del Presidente Carlos Mesa, ocurrida en junio de 2005, apenas unos meses después de diciembre de 2004, fecha de edición del documento. Así, pese a su denominación oficial, por los contenidos y los procedimientos para su elaboración, así como su muy tardía divulgación, es imposible considerarlo como un Libro Blanco.

Colombia, por su parte, dio a conocer un documento conceptual respecto a las orientaciones de sus políticas de seguridad y defensa en 2003, cuyos contenidos están muy alejados de los requerimientos sustantivos y procedimentales exigidos a un libro blanco. Recién en 2015 aparece un segundo documento, que refleja los cambios en la orientación de la política de defensa y seguridad introducidos por el Presidente Juan M. Santos. Sin 
embargo, su contenido y la ausencia de procesos de consulta lo vuelven a ubicar como documento de política de defensa.

En Uruguay, diversos Ministros de Defensa Nacional divulgaron documentos en tres diferentes momentos del período considerado. Ninguno de ellos podría catalogarse como libro blanco; los dos primeros - 1999 y 2005 - por el proceso cerrado de su elaboración al interior del Ministerio de Defensa y el más reciente (2014), que contempló una instancia muy limitada de consulta más formal que sustantiva -, constituye por su contenido - como su propio título lo indica - un documento de política de defensa.

En cuanto a Paraguay, en 1999 divulgó un denominado Plan Global que parece dirigido esencialmente a objetivos de racionalización administrativo-burocrática de su sector de la defensa y presenta una descripción detallada de la orgánica del MDN junto con las funciones, metas y actividades de cada una de sus reparticiones y servicios para el período 1999-2003. Un segundo documento, con definiciones genéricas y objetivos del Ministerio de Defensa, denominado "Política de Defensa Nacional", fue aprobado por el Consejo de la Defensa Nacional y divulgado también en 1999. De cualquier manera, ambos documentos distan de los requerimientos sustantivos para calificar como Libros Blancos. Desde el punto de vista procedimiental, no hay referencias de que su elaboración haya contemplado alguna forma de consulta. En todo caso, ambos fueron elaborados en el ámbito del Ministerio de Defensa, según las tradiciones de reserva características del establishment militar paraguayo

Finalmente Venezuela aparece como el único país de la región que no registra ninguna publicación durante las últimas dos décadas. En el marco de las ríspidas relaciones políticas entre la revolución boliviariana y EEUU, a quien Caracas acusa recurrentemente de promover planes de desestabilización y ubica como su principal amenaza militar, el clima político aparece como poco propicio a la transparencia en cuestiones de defensa. Por otra parte, las tradicionalmente complejas relaciones entre Venezuela y Colombia, agravadas por el papel de Bogotá como socio privilegiado de Washington en Sudamérica, constituyen factores de tensión bilateral que ha generado más de una crisis y promueven la desconfianza mutua. ${ }^{56}$

\section{ALGUNAS CONCLUSIONES FINALES}

De lo planteado hasta aquí es posible concluir que la receptividad mostrada por los gobiernos sudamericanos a la iniciativa de elaborar y difundir libros blancos de defensa ha sido al menos escasa. Ello induce intentar extraer algunas explicaciones generales. 
Para comenzar conviene recordar dos cuestiones que fueron analizadas con algún detenimiento en las primeras secciones del artículo y que pueden caracterizarse como fenómenos estructurales que actuaron como trabas; una de tipo cultural y otra política.

La primera refiere a la dificultad de incorporar una práctica gubernamental asociada a una cultura política ajena a las tradiciones de gobierno predominantes en la región. Por otra parte, los libros blancos de defensa tuvieron como impulsores originales a la OEA y en particular a EEUU. Si en un principio - durante la década de los 90' - ello generó cierta receptividad en los Ministerios de Defensa de la región, dicha empatía sólo excepcionalmente se tradujo en la publicación de libros blancos. Hacia fines de los años 90', la crisis del Consenso de Washington y la transformación política que América del Sur experimentó, coincidiendo con el inicio del nuevo milenio, fueron desplazando a la OEA de su papel como principal organismo regional, al tiempo que Sudamérica quedó relegada en las prioridades, tanto del Departamento de Defensa como de la Secretaría de Estado de EEUU.

Así, durante el período analizado el organismo hemisférico fue cayendo en un proceso de progresiva irrelevancia política, correlativo con el surgimiento y desarrollo de nuevos organismos regionales - como Unasur, el Alba o Celac -, todos los cuales, además, excluyeron la participación de EEUU.

Esta asociación entre libros blancos de defensa, OEA y política norteamericana podría haber tenido algún papel en la trayectoria de los libros blancos de defensa en América del Sur, una región que durante el período considerado - 1995 a 2015 - vivió una situación inédita por los bajos niveles de influencia/hegemonía de EEUU en sus asuntos militares y de defensa. En ese sentido, como precisó más arriba, el Consejo de Defensa de Unasur optó por medidas de fomento de la confianza mutua de clara impronta tecnocrática, que por no incluir la dimensión democrática o procedimental, resultaron más amigables para los establishments militares - y también diplomáticos - de la región.

Por otra parte, originalmente los libros blancos de defensa fueron promovidos como una medida de fomento de la confianza mutua a la cual se incorporó una dimensión democrática que resultaba funcional al interés norteamericano de redefinir el papel político que, a lo largo del siglo XX, habían tenido las fuerzas armadas de la región.

Así, Canadá, recién ingresada a la OEA, fue encargada de introducir su experiencia en la comisión de la Conferencia de Williamsburg en la que por primera vez se consideró conveniencia de promover la elaboración de libros blancos de defensa. En efecto, Canadá había publicado un documento de ese tipo un año antes (1994) y posteriormente presentó a la Comisión de Seguridad Hemisférica de OEA dos documentos con 
Directrices para la Elaboración de Libros Blancos en octubre de 2002. ${ }^{57}$ Estos documentos fueron la base para las definiciones y recomendaciones de OEA sobre el tema.

La iniciativa se introdujo bajo el rótulo de medida de fomento de la confianza mutua, pero contuvo también una dimensión de política doméstica vinculada con la democratización del sector de la defensa en la región; inclusión de nuevos actores y fortalecimiento del papel de las autoridades políticas electas.

A partir de la constatación de que sólo algunos países han adoptado la práctica de publicar Libros Blancos de Defensa, en el artículo se ensayaron algunas explicaciones del fenómeno.

En primer lugar; se exploraron las razones estructurales que explican la difícil implantación de los Libros Blancos de Defensa en Sudamérica.

Ellas podrían definirse como de carácter cultural y más específicamente de filosofía política de gobierno. Incompatibilidades y resistencias que resultan de tradiciones muy arraigadas de cultura de gobierno y manejo de políticas públicas en la región, asociadas al legado colonial de origen europeo continental, la influencia napoleónica y el anclaje jurídico en el derecho romano. El fenómeno no sólo refiere sólo a los países de herencia hispánica. En el caso del Brasil, sus raíces imperiales incluso acentúan dichos rasgos de cultura política. En efecto, en nuestros países y sus sociedades la adopción de prácticas de transparencia y accountability en el manejo del gobierno y de las políticas públicas representan procesos de aprendizaje dificultoso y lento.

Estas resistencias e incompatibilidades se acentúan en la arena de las políticas de defensa nacional. En primer término, las fuerzas armadas, como cualquier burocracia pública profesional, custodian celosamente su monopolio técnico, una tendencia reforzada por la larga tradición de manejo de las políticas militares y de defensa que, por otra parte, poseen urbi et orbi una fuerte impronta de reserva y confidencialidad. Así, en Sudamérica ${ }^{58}$ - como dos caras de una misma moneda -, mientras las instituciones militares poseen arraigadas tradiciones de cuasi autogobierno en el sistema político y la sociedad civil predominan la falta de interés, el limitado conocimiento y la casi nula experiencia respecto de la conducción efectiva de las políticas vinculadas a la defensa nacional (Pion-Berlin 2005 y 2008; González Guyer 2013).

La baja prioridad política de la defensa en la agenda de mayoría de los gobiernos de los países de Sudamérica dificulta la implantación de una iniciativa que requiere voluntad política para superar desconfianzas y resistencias, en tanto la publicación del Libro Blanco de Defensa supone transparentar los aspectos más delicados de estas políticas y al mismo tiempo dar voz a actores políticos y sociales tradicionalmente ajenos al establishment de la defensa. 
No es extraño que la primera ola de documentos de defensa (Argentina, Bolivia, Brasil, Chile, Colombia, Ecuador, Paraguay, Perú y Uruguay), registrada entre fines del Siglo XX y el primer lustro del Siglo XXI haya sido elaborada al interior de los Ministerios de Defensa, con poca o ninguna consulta con otros actores. ${ }^{59}$ Ella podría denominarse ola hemisférica, por la influencia que en ella tuvo el Centro Hemisférico de Estudios de Defensa (CHDS) de la National Defense University de Washington DC $^{60}$ y también la CSH de OEA.

A partir de la segunda mitad de los años 2000 se perfiló un proceso con características nuevas; si bien se redujo el número de documentos de defensa publicados, con la excepción de Surinam ${ }^{61}$ aumentó el número de países que optaron por incorporar mecanismos de consulta con actores ajenos al Ministerio de Defensa.

Esta segunda ola además, presenta un carácter más endógeno. Esto es, resulta posible identificar más claramente la existencia de motivaciones vinculadas con necesidades y objetivos específicos de política doméstica de sus gobiernos.

En efecto, en Ecuador a partir de la elección del Presidente Rafael Correa en 2006, se iniciaron cambios significativos en la concepción y en la organización de la defensa y la seguridad que parecen haber sido la principal motivación para la elaboración y divulgación, desde entonces, de tres documentos de defensa.

En los casos de Chile y Argentina, sus Libros Blancos de Defensa presentan cierto paralelismo en el tiempo. En sus inicios su publicación puede vincularse con el activo proceso de normalización de sus relaciones bilaterales, luego de la crisis por sus diferendos limítrofes de fines de los años $70{ }^{\prime}{ }^{62}$ Pero en años más recientes, los Libros Blancos de Defensa de ambos países aparecen relacionados principalmente con la política de fortalecimiento de la conducción política de la defensa nacional y que implementaron ambos gobiernos. Hay que precisar que dichas similitudes se verifican a pesar de las realidades significativamente divergentes en sus políticas de defensa, dentro de un marco general de subordinación militar a las autoridades electas.

En efecto, mientras en Chile sus fuerzas armadas conservan influencia política y prestigio, además de un significativo potencial de combate apoyado por un moderno equipamiento, Argentina luego de la derrota de Malvinas fue escenario de la pérdida de peso político y prestigio de sus Fuerzas Armadas desembocando en muy bajos niveles de inversión que han comprometido incluso sus capacidades operativas.

Finalmente Brasil, con su recién publicado segundo Libro Blanco de Defensa y en tanto potencia emergente y actor político de nivel global, ha emprendido un proceso de rediseño de sus capacidades militares e inclu- 
so del papel de la defensa en su política de desarrollo económico y científico-tecnológico, explicitado desde su Estrategia Nacional de Defensa de $2008{ }^{63}$ En tales condiciones el sector de la defensa nacional de Brasil adquirió un nivel de relevancia sin paralelo en la región. Los ambiciosos proyectos de producción del submarino nuclear, de aviones de combate ${ }^{64}$ $\mathrm{y}$ aviones de transporte militar, ${ }^{65}$ se ubican como las mayores inversiones estatales junto a los planes de Petrobras en la plataforma marítima. No es extraño que, en tales condiciones, el Parlamento brasileño haya incluido la obligación para el Ministerio de Defensa de mantener actualizados una serie de documentos, entre ellos el Libro Blanco de Defensa, el cual además debe incluir un conjunto de información que se detalla en la Ley Complementar 136/2010. ${ }^{6}$ Por lo demás, desde la creación del Ministerio de Defensa, de forma gradual y muy negociada, los gobiernos brasileños han ido incrementando su control político sobre sus tradicionalmente poderosas y autónomas fuerzas armadas. Complementariamente, la actualización periódica del Libro Blanco es una buena guía para las diversas agencias vinculadas a la defensa y para la propia sociedad civil.

Del análisis presentado surge que, si bien generalmente se encuadra a los libros blancos de defensa dentro de la batería de medidas dirigidas a fomentar y/o fortalecer la confianza mutua entre países con intereses contrapuestos que pueden derivar en conflictos militares, la realidad parece mostrar que la principal motivación de los gobiernos que han asumido esta práctica novedosa para América del Sur, no se ubica allí.

Sin cuestionar el potencial de los Libros Blancos de Defensa como instrumentos que contribuyen a prevenir o des-escalar conflictos, del análisis resulta que los gobiernos sudamericanos los han utilizado preferentemente con el fin de perfeccionar el funcionamiento de su sector de la defensa nacional, para legitimar sus políticas y/o para promover la participación e interés del sistema político y la sociedad civil en la temática.

En resumen. Los Libros Blancos de Defensa, aunque introducidos en la región como un instrumento de política exterior, sólo fueron adoptados principalmente como herramienta de política doméstica, por unos pocos gobiernos sudamericanos.

\section{BIBLIOGRAFÍA}

Atria, Rodrigo. 2003. Libros Blancos, una Base Común para su Elaboración. Seminario REDES 2003, CHDS, Santiago de Chile.

Barrachina, Carlos. 2008. Programa Interno de Medidas de Confianza Mutua: los Libros Blancos en América Latina bajo una Perspectiva Comparada. In Sepúlveda, 
Isidro; Alda, Sonia (Ed. ), La Administración de la Defensa en América Latina. Vol. III: Estudios comparados. Madrid: IUGM. 423-446.

Celi, Pablo. 2014. Análisis de la Dinámica del Escenario Regional. Ciclo de Debates Preparatorios. Libro Blanco de la Defensa 2014. Buenos Aires: Ministerio de Defensa. Disponible en: <http://www. libroblanco. mindef. gov. ar/files/ponencia_celi. pdf $>$. Acceso en: 15 fev. 2015.

Collier, Ruth Berins; Collier, David. 1991. Shaping the Political Arena. Princeton University Press, New Jersey.

García Gallegos, Berta. 2008. Los libros Blancos en la Región Andina. In Sepúlveda, Isidro; Alda, Sonia (Ed. ), La Administración de la Defensa en América Latina. Vol. III: Estudios comparados. Madrid: IUGM. 447-466.

González Guyer, Julián. 2013. Relaciones civiles-militares en su contexto. La perdurabilidad del control político civil en Sudamérica. In Pion-Berlin, David; Ugarte, José Manuel (comp. ), Organización de la Defensa y Control Civil de las Fuerzas Armadas en América Latina. Buenos Aires: Ed. Jorge Baudino. 99-144.

2008. Los Libros Blancos en los Países del Conosur. In Sepúlveda, Isidro; Alda, Sonia (Ed. ), La Administración de la Defensa en América Latina. Vol. III: Estudios comparados. Madrid: IUGM. 467-494.

2010. Rara Avis: los Libros Blancos de Defensa en el Cono Sur. Disponible en: $<$ http://www. libroblanco. mindef. gov. ar/files/GUYER\%20Rara\%20avis\%20 Los\%20libros\%20blancos\%2Ode\%2Odefensa\%20en\%20el\%20cono\%20sur. pdf>.

Guzzini, Stefano. 2013. The Ends of International Relations Theory: Stages of Reflexivity and Modes of Theorizing. European Journal of International Relations, 9, 3, 521-541.

Hayes, Margareth D. 2001. El Libro Blanco de la Defensa: el caso de EEUU. In Quintana, Juan Ramón (Ed. ), Libros Blancos de Defensa. Concertación Política y Diseño Estratégico. La Paz: Ministerio de Defensa Nacional (UDAPDE). 119-126.

Mora, Frank; Palá, Antonio. 1999. US Arms Transfer Policy for Latin America. Lifting the Ban on Fighter. Air and Space Power Journal, Spring, 76-92.

Pion-Berlin, David. 2005. El Manejo Político de los Militares en Latinoamérica. Military Review, mar. -abr. , 52-67.

2008. Militares y Democracia en el Nuevo Siglo. Revista Nueva Sociedad, Buenos Aires, 213, 50-63. 
Pacheco Gaitán, Guillermo. 2008. Los Libros Blancos en Centroamérica: ¿un paso para consolidar medidas de confianza? In Sepúlveda, Isidro; Alda, Sonia (Ed. ), La Administración de la Defensa en América Latina. Vol. III: Estudios comparados. Madrid: IUGM. 495-517.

Runza, Ricardo A. 2004. Las Relaciones Argentino-Chilenas de Defensa. Análisis y Evaluación desde la Perspectiva del Comité Permanente de Seguridad. Lateinamerika Analysen, 8, IIK, junio. 137-166.

Soto Silva, Julio E. 2016. Elementos para la elaboración de un Libro de Nacional. Análisis Comparado de libros blancos y estrategias de Seguridad Nacional de países europeos y continentales. Revista de Estudios en Seguridad Internacional, 2, 2, $57-100$.

Taylor, Claire. 2010. A Brief Guide to Previous British Defence Reviews. House of Commons Library, Londres. Disponible en: <http://www. parliament. uk/briefing-papers/SNO57 14. pdf $>$. Acceso en: 04 fev. 2015. 


\section{NOTAS}

1. Ver los acuerdos sobre medidas de confianza mutua en el Acta Final de la Conferencia de Helsinki de 1975. Disponible en: <http://www 1. umn.edu/humanrts/osce/basics/finact75.htm> y también <http:// www.osce.org/fsc/41368? download=true>. Acceso en: 3 mar. 2015.

2. Reunión de Cancilleres de OEA, 4 jun. 1991.

3. Ver https://docs.google.com/document/d/1S8MKimYXIDgcBd1gSytVicih-GMetPijjuohUZYGjo/edit (acceso 01/03/2015)

4. David Pion-Berlin (2005, 65-66) calificó a los Libros Blancos de Defensa publicados en América Latina hasta 2004 como propaganda y ejercicios de $[\ldots]$ "ofuscación transparente". Ver también Barrachina (2008).

5. Ver <http://ceed.unasursg.org/Espanol/O2-Lineas/O2.1-Gastos-Def. html>. Acceso en: 27 jul. 2017.

6. Disponible en: <http://www.oas.org/consejo/sp/resoluciones/res829. asp>. Acceso en: 07 fev. 2017.

7. Ver http://www.nationalarchives.gov.uk/cabinetpapers/help/glossaryw.htm\#White_Paper>. Acceso en: 10 fev. 2015.

8. La traducción es del autor. Ver <http://www.parliament.uk/site-information/glossary/white-paper/>. Acceso en: 04 fev. 2014.

9. La traducción es del autor. Ver <http://www.parliament.uk/site-information/glossary/green-papers/>. Acceso en: 10 fev. 2015.

10. Principalmente, además de las fuentes regionales, se revisaron los Archivos Nacionales y la página web del Parlamento de Gran Bretaña.

11. El denominado Sandys White Paper Review por haber sido elaborado por el Ministro de Defensa Duncan Sandys. Ver <http://www.nationalarchives.gov.uk/cabinetpapers/themes/policy-reviews.htm>. Acceso en: 5 fev. 2015.

12. Ver por ejemplo <http://airminded.org/2010/12/04/the-h-bomberwill-always-get-through/> . Acceso en: 4 fev. 2015.

13. Ver <http://www.cmhg.gc.ca/cmh/page-708-eng.asp>. Acceso en: 14 fev. 2015.

14. Ver <http://www.oas.org/csh/spanish/doclibrdefCanada.asp>. Acceso en: 14 fev. 2015.

15. Disponible en: <http://www.mqup.ca/canada-s-national-defence--volume-1-products-9780889117907.php\#!prettyPhoto>. Acceso en: 15 fev. 2015.

16. Conferencia para la Seguridad y la Cooperación en Europa, conocida también como Conferencia de Helsinki donde comenzó a reunirse a partir de 1975. En 1995, se transformó en Organización con el nombre de OSCE (ver <http://www.osce.org/who/timeline>, acceso en: 3 fev. 2015). 
17. Ver por ejemplo el programa de este tipo de actividades cumplidas en 2016 entre EEUU y la República Popular China en <https:// www.defense.gov/Portals/1/Documents/pubs/2016\%20China\%20 Military\%20Power\%20Report.pdf>, p. 4-101 y Appendix I. Acceso en: 10 jul. 2017.

18. Ver el cuadro más abajo.

19. Centro Regional de las NNUU para la Paz, el Desarme y el Desarrollo en América Latina y el Caribe.

20. OEA/Ser. G CP/CSH-504/O2 corr. del 15 noviembre 2002 en <http://www.oas.org/CSH/spanish/doclibrdef.asp>. Acceso en: $15 \mathrm{fev}$. 2017.

21. También la V Conferencia de Ministros de Defensa de las Américas, celebrada en Santiago de Chile en 2002, incluyó la publicación de Libros Blancos de Defensa como una de las iniciativas para promover la transparencia en las políticas de defensa y seguridad pública e hizo suyo el documento de la CSH (ver \#22 en <http://www.resdal.org/Archivo/ doo00196.htm>. Acceso en: 15 jun. 2017.

22. Ellas, precisa el LEDPND, deberán brindar su asesoramiento técnico a la elaboración del Libro Blanco.

23. En 1995 la Fuerza Aérea de Chile inició gestiones para adquirir aviones de combate de última generación.

24. OEA/Ser.G - CP/RES. 829 (1342/O2). Ver <http://www.oas.org/ consejo/sp/resoluciones/res829.asp>. Acceso en: 5 mai. 2017.

25. Disponible en: <http://www.oas.org/juridico/spanish/ago1/ agres_1801.htm>. Acceso en: 9 fev. 2015.

26. Ver en <http://www.oas.org/CSH/spanish/doclibrdef.asp>. Acceso en: 13 fev. 2015.

27. El documento no tiene fecha y no está accesible actualmente.

28. Disponible en: <http://www.jid.org/jid-anuncios/agendaparaeltallerdellibroblancodehaiti>. Acceso en: 5 jun. 2017.

29. Ver < http://www.oas.org/CSH/spanish/doclibrdef.asp\#libros>. Acceso en: 11 jun. 2017.

30. Ver en <http://www.libroblanco.mindef.gov.ar/files/ponencia_celi.pdf $>$. Acceso en: 01 nov. 2014.

31. Acerca del CREES ver la ilustrativa entrevista a su director (<https:// dialogo-americas.com/es/articles/el-centro-regional-de-estudios-estrategicos-en-seguridad-de-colombia-se-enfoca-en-amenazas-regionales $>$. Acceso en: 18 jun. 2017.

32. Disponible en: <http://ceed.unasursg.org/Espanol/o9-Downloads/ Biblioteca/RSGD-2006-2010_ESP.pdf>. Acceso en: 18 jun. 2017. 
33. Disponible en: <http://ceed.unasursg.org/Espanol/o9-Downloads/ Biblioteca/RSGAD-2011-2013-WEB.pdf>. Acceso en: 18 jun. 2017.

34. Disponible en: <http://ceed.unasursg.org/Espanol/o9-Downloads/ Biblioteca/RSGAD-2006-2015-WEB.pdf>. Acceso en: 18 jun. 2017.

35. Guzzini se apoya en dos sugerentes textos de Norbert Elías: La Sociedad Cortesana y Los Alemanes.

36. El listado de la CSH de OEA está notoriamente desactualizado (ver $<$ http://www.oas.org/csh/spanish/doclibrdef.asp\#libros $>$ ).

37. En Brasil, la Ley Complementar establece plazos concretos al Ministerio de Defensa para presentar las actualizaciones al Parlamento. En la Argentina, en cambio, las revisiones periódicas no están normadas legalmente.

38. Los Ministerios de Defensa de Brasil y Argentina organizaron conjuntamente el workshop denominado "Experiencias de Países Suramericanos en la Formulación de Libros Blancos de Defensa”, en noviembre de 2014.

39. Ver <http://www.defensa.cl/discursos/intervencion-del-ministro-de-defensa-nacional-en-el-seminario-con-que-argentina-inicia-el-proceso-de/>. Acceso 3 jun. 2017.

40. Disponible en: <http://www.oas.org/csh/spanish/doclibrdef.asp\#libros $>$. Acceso en: 14 jun. 2017.

41. Una fuente complementaria importante para ello fue un trabajo elaborado por el Ministerio de Defensa de Argentina que ya no se encuentra disponible on-line.

42. Uno a través del Centro de Estudios Hemisféricos (CHDS) de la National Defense University (NDU) y el otro directamente por el Comando Sur.

43. En 1995, la Fuerza Aérea chilena inició contactos con EEUU, Francia y Suecia para renovar su flota de caza de combates. Dos años después (agosto de 1997), el Presidente Clinton levantó la interdicción de ventas de equipo militar avanzado a Latinoamérica, aprobada en 1977 por la Directiva Presidencial 13 (PD 13) del Presidente Carter (Mora; Palá 1999, 77).

44. Los estrategas chilenos señalan que, con conflictos en todas sus fronteras y una escasa profundidad estratégica como consecuencia de su geografía, Chile está obligado a lograr la superioridad militar y a desarrollar capacidades militares ofensivas.

45. Conviene recordar que Gonzalo García Pino, uno de los autores del artículo citado, fue asesor del Ministro de Defensa (1994-1997), Subsecretario de Marina (2005-2006) y Subsecretario de Guerra (2006-2010) de Chile. 
46. En realidad, una burocracia eficaz bajo adecuada orientación de los responsables políticos del Ministerio, es suficiente para elaborar un documento cuyos contenidos se ajusten a sus requerimientos sustantivos.

47. Ciertamente, son muy escasas las que se dedican a temas de defensa nacional y/o seguridad internacional.

48. Organismo de diálogo bilateral a nivel de Viceministros de Relaciones Exteriores y de Defensa, creada en 1995, que permite coordinar aspectos de la política exterior y de defensa de ambos países. Incluye actividades a nivel de los Estados Mayores de Defensa y hasta la generación de una unidad militar bi-nacional para operaciones de paz - Batallón Cruz del Sur - que, sin embargo, no ha sido desplegado hasta el presente.

49. Disponible en: $<$ http://www.mrecic.gov.ar/argentina-chile-reunion-en-cancilleria-del-comite-permanente-de-seguridad>. Acceso en: 12 jun. 2017.

50. Junto al Libro Blanco, el Poder Ejecutivo debe presentar al Parlamento los documentos "Política de Defensa" y "Estrategia de Defensa" (artículo $9^{\circ} \$ 3^{\circ}$ de la Ley Complementar $\left.n^{\circ} 136 / 2010\right)$. Además el art. 12 obliga al MDN a elaborar su presupuesto en base a las prioridades de la "Estrategia Nacional de Defensa". Ver <http://www.planalto.gov. br/ccivil_03/leis/lcp/lcp136.htm>. Acceso en: 10 jun. 2017.

51. Comisión Nacional de Investigación.

52. La divulgación pública y la presentación y del Libro Blanco al Congreso se produjo en plena crisis política y ello seguramente conspire contra la tramitación del asunto.

53. Además de Libro Blanco, los otros documentos son la Política de Defensa Nacional y la Estrategia de Defensa Nacional.

54. Ver González Guyer 2008, 478 y $2010,9$.

55. Ver <http://www.oas.org/csh/spanish/documentos/Bolivia\%20-\%20 2004.pdf>. Acceso en: 13 fev. 2015.

56. Como se ya vio, Colombia tampoco publicó su Libro Blanco de Defensa. 57. Ver CP/CSH-496/o2 y CP/CSH-492/o2 en <http://www.oas.org/ csh/spanish/doclibrdef.asp>. Acceso en: 20 jun. 2017.

58. Enseguida de intentará fundamentar las razones que explican los casos excepcionales de la región.

59. Perú, Chile y Argentina son las excepciones.

60. En 1997 como una consecuencia directa de los llamados Acuerdos de Williamsburg, elaborados por el Secretario de Estado William Perry (ver <http://dialogo-americas.com/es/articles/rmisa/features/regional_news/2013/04/15/chds-perry>, acceso en: 6 mar. 2017). En sus primeros años el curso estrella (ejercicio Tabula Rasa) consistía en una actividad teórico-práctica de elaboración de la política de defensa de un país hipotético. Si bien muchos civiles pasaron por sus aulas, también lo 
hicieron muchas decenas de oficiales militares, algunos de cuales reprodujeron aquel ejercicio teórico elaborando documentos de política de defensa en sus países (el documento publicado en 1999 por el Ministerio de Defensa de Uruguay siguió dicho patrón).

61. Surinam permanece, a pesar de su presencia en Unasur, alejado de los procesos regionales y es poca la información disponible respecto a las motivaciones de su gobierno para publicar un documento de defensa.

62. La instalación del Comité Permanente de Seguridad Argentina-Chile (Comperseg) se produce en 1995 y posteriormente se inicia la creación de la Brigada bi-nacional "Cruz del Sur".

63. La crisis económica y política ha debilitado las ambiciones brasileñas, pero el potencial de Brasil y el legado que dejó la política exterior del período de gobierno del presidente Lula da Silva permanecen.

64. Si bien Brasil comprará los Gripen NG a Suecia, el contrato incluye transferencia de tecnología y la producción de los aviones en Brasil (<http://agenciabrasil.ebc.com.br/es/geral/noticia/2014-10/brasil-comprara-cazas-gripen-de-suecia >, acceso en: 7 mar. 2015.

65. El Embraer KC-390 ya ha sido presentado y tiene condiciones para competir con el célebre Hércules norteamericano (<http://www.republica.com.uy/brasil-presento-su-nuevo-avion-militar-de-transporte/485272/>, acceso en: 8 mar. 2015.

66 . Ver más arriba. 


\section{LIBROS BLANCOS DE DEFENSA EN SUDAMÉRICA: ¿POLÍTICA EXTERIOR O POLÍTICA DOMÉSTICA?}

\section{RESUMEN}

El Ministerio de Defensa Nacional de Brasil ha sometido a consideración del Congreso la segunda versión de su Libro Blanco de Defensa en noviembre de 2016. Argentina presentó su tercera edición del documento a fines de 2015 y se ha anunciado que Chile prepara su cuarta revisión. Aunque han transcurrido dos décadas desde la divulgación del primer documento sudamericano de este tipo, bajo el título de Libro de la Defensa Nacional de Chile, los libros blancos de defensa están lejos de haber sido adoptados como práctica corriente por los gobiernos de Sudamérica. El artículo propone algunas explicaciones del fenómeno. Además de sugerir una caracterización de este tipo de documento de política pública y relevar sus limitaciones y dificultades, expone sintéticamente la historia de su introducción en la región, para concluir que si bien los Libros Blancos de Defensa fueron inicialmente promovidos como una medida de fomento de la confianza mutua por la OEA, las motivaciones reales de los únicos tres gobiernos que los adoptaron como práctica corriente no parecen responder a dicha lógica.

Palabras clave: Libros Blancos de Defensa; Sud América; Medidas de confianza mutua.

\section{ABSTRACT}

The Brazilian National Defense Ministry has delivered the second version of its Defence White Paper in November 2016. Argentina edited its third revision in December 2015 and Chile has announced that its fourth version is forthcoming. These events coincide with the $2 \mathrm{O}^{\text {th }}$ anniversary of the first South American country's Defense White Paper, published in 1997 by the Chilean government. Nevertheless, this kind of document is far of being an extended governmental practice in the region. The article proposes some explanations about the poor regional record achieved by this Anglo-Saxon political procedure. It also advances some historical references about the Defense White Papers' arrival to Latin America and concludes that, even if initially proposed as a confidence building measure, the rationale of the very few South American Defense White Papers published since 1997 , lies in the domestic political realm.

Keywords: Defense White Papers; South America; Confidence building measures. 